\title{
Riluzole-induced Lung Injury in Two Patients with Amyotrophic Lateral Sclerosis
}

\author{
Takuya Kakuta ${ }^{1}$, Hirokuni Hirata ${ }^{1}$, Sayo Soda ${ }^{1}$, Taichi Shiobara ${ }^{1}$, Mineaki Watanabe ${ }^{1}$, \\ Masamitsu Tatewaki ${ }^{1}$, Fumiya Fukushima ${ }^{1}$, Kazuyuki Chibana ${ }^{1}$, Kumiya Sugiyama ${ }^{1}$, \\ Masafumi Arima ${ }^{1,2}$, Honma Koichi ${ }^{3}$, Takeshi Fukuda ${ }^{1}$ and Yasutsugu Fukushima ${ }^{1}$
}

\begin{abstract}
Riluzole has recently been proven as the first effective drug for the treatment of amyotrophic lateral sclerosis (ALS). We report two rare cases of lung injury caused by riluzole therapy in patients with ALS. Chest radiographs showed bilateral lower lobe, dorsal-dominant ground glass opacity, and/or consolidation. A drug lymphocyte stimulation test (DLST) of peripheral blood or bronchoalveolar lavage cells was positive for riluzole. Histopathological examination of lung biopsy specimens revealed lung injury without fungoid granuloma, vasculitis, or diffuse alveolar damage. To the best of our knowledge, this is the first report of riluzoleinduced lung injury with positive DLST results.
\end{abstract}

Key words: riluzole, lung injury, amyotrophic lateral sclerosis, drug lymphocyte stimulation test

(Intern Med 51: 1903-1907, 2012)

(DOI: 10.2169/internalmedicine.51.6522)

\section{Introduction}

Drug-induced interstitial lung disease can be caused by an increasing number of medications. Riluzole has recently been proven as the first effective drug for the treatment of amyotrophic lateral sclerosis (ALS) (1). Here we report two rare cases of lung injury caused by riluzole therapy in patients with ALS.

\section{Case Reports}

\section{Case 1}

A 69-year-old woman was diagnosed with ALS 21 months before presentation. Riluzole $50 \mathrm{mg}$ twice daily was started 9 months after the diagnosis. Three weeks after start of treatment, she presented to our hospital with a 2-week history of dyspnea on exertion and general fatigue.

Physical examination revealed no obvious abnormalities, and oxygen saturation on room air was $93 \%$. Chest radiography showed increased ground glass opacity (GGO) in bilateral lower lungs in comparison to the prior 5 months. Chest computed tomography (CT) (Fig. 1a) revealed bilateral lower lobe, dorsal-dominant GGO, and consolidation. Arterial blood gas analysis (room air) indicated $\mathrm{pH}$ 7.441, $\mathrm{PCO}_{2}$ 38.6 Torr, $\mathrm{PO}_{2}$ 77.7 Torr, $\mathrm{HCO}_{3} 25.9 \mathrm{mEq} / \mathrm{L}$, and $\mathrm{BE}$ $2.2 \mathrm{mEq} / \mathrm{L}$. Additional laboratory test results were as follows: white blood cell count $11,200 / \mu \mathrm{L}$ (neutrophils $77.9 \%$, eosinophils $2.5 \%$, lymphocytes $11.9 \%$, monocytes $7.8 \%$, basophils $0.4 \%$ ); serum C-reactive protein $0.73 \mathrm{mg} / \mathrm{dL}$ (nor$\mathrm{mal},<0.3 \mathrm{mg} / \mathrm{dL}$ ); creatinine $0.77 \mathrm{mg} / \mathrm{dL}$ (normal, 0.46-0.82 $\mathrm{mg} / \mathrm{dL}$ ); lactate dehydrogenase 286 IU/L (normal, 200-400 IU/L); Krebs von den Lungen-6 (KL-6) 518 U/mL (normal, $<500 \mathrm{U} / \mathrm{mL}$ ); surfactant proteins (SP)-D; $293 \mathrm{ng} / \mathrm{mL}$ (nor$\mathrm{mal},<110 \mathrm{ng} / \mathrm{mL}$ ); cytoplasmic-anti-neutrophil cytoplasmic antibody $<10$ EU; perinuclear-anti-neutrophil cytoplasmic antibody <10 EU; anti-nuclear antibody 40× (speckled pattern); anti-Sjögren's syndrome (SS) A (anti-SSA/Ro) negative $(<20$ index); and stimulation index $(\mathrm{SI})$ value on a drug

\footnotetext{
${ }^{1}$ Department of Pulmonary Medicine and Clinical Immunology, Dokkyo Medical University, Japan, ${ }^{2}$ Department of Developmental Genetics, Chiba University Graduate School of Medicine, Japan and ${ }^{3}$ Department of Anatomic and Diagnostic Pathology, Dokkyo Medical University, Japan

Received for publication September 7, 2011; Accepted for publication April 3, 2012

Correspondence to Dr. Hirokuni Hirata, hirokuni@dokkyomed.ac.jp
} 

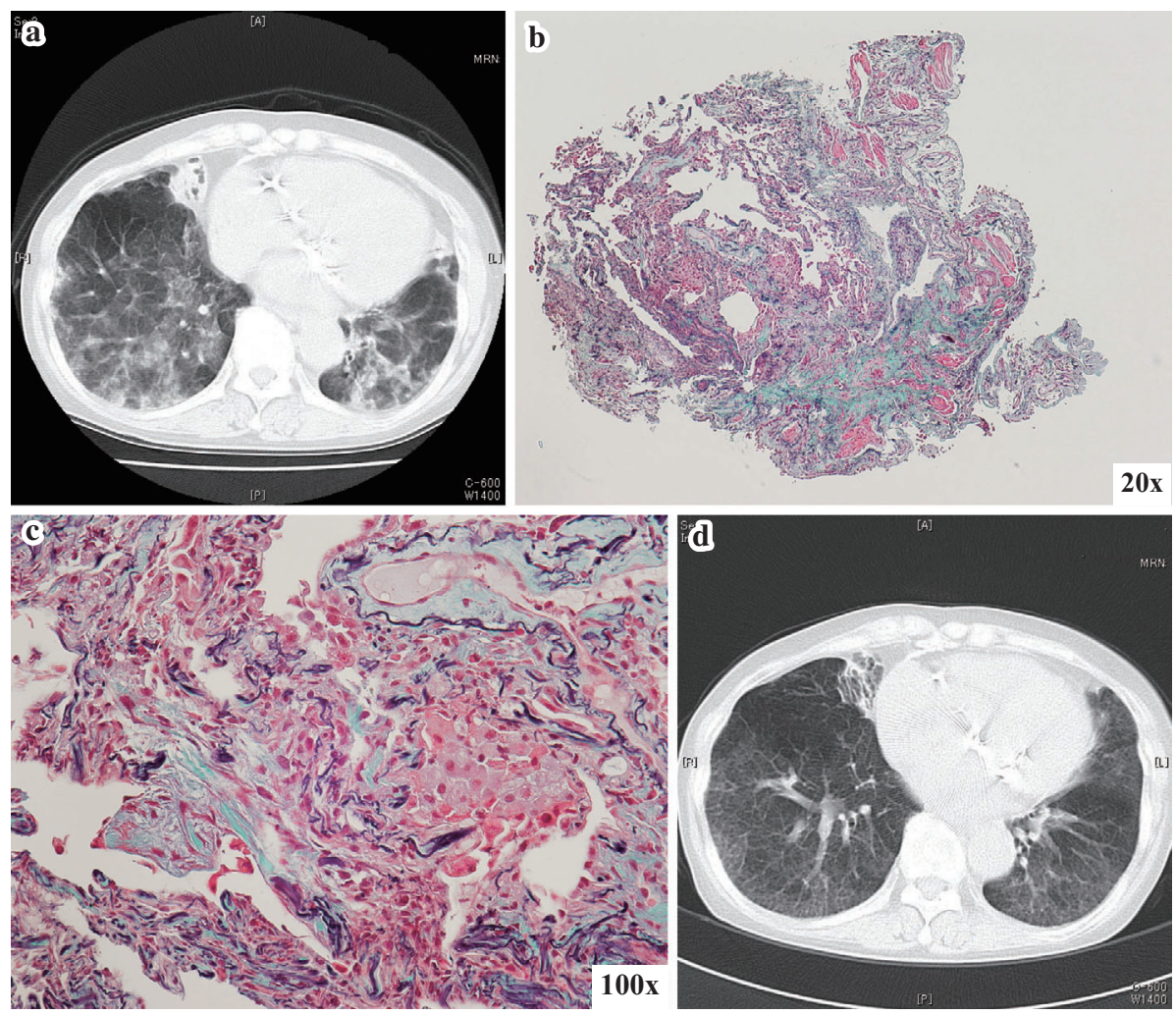

Figure 1. Case 1: Radiological and histological findings. (a) Chest computed tomography (CT) image taken 3 weeks after the start of riluzole therapy. (b) Histological examination of Elastica-Masson (E.M)-stained biopsy specimens from the right $\mathrm{S8}$ region revealed scattered foci of intraalveolar fibrosis in low power view $(\times 20)$. (c) The high power view $(\times 100)$ demonstrated intraalveolar fibrosis adherent to the alveolar septa and thus incorporated into the interstitium. (d) Chest CT scan taken 2 weeks after starting prednisolone treatment. When compared with the images from before prednisolone treatment, these images demonstrate clear improvement in ground-glass opacity and consolidation.

lymphocyte stimulation test (DLST) $284 \%$ (control $134 \mathrm{cpm}$ vs. riluzole $381 \mathrm{cpm})$. In the DLST, performed for outpatients by SRL Inc., peripheral blood mononuclear cells (PBMCs) separated by Ficoll-Hypaque density gradient centrifugation and/or bronchoalveolar lavage (BAL) fluid are quantitatively assessed for mitogenic activity by ${ }^{3} \mathrm{H}-$ thymidine incorporation. The SI is defined as counts per minute with riluzole divided by counts per minute without (as the negative control). The DLST was considered positive if the SI was $180 \%$ or greater. Pulmonary function data were as follows: FVC $1.27 \mathrm{~L}, \% \mathrm{FVC} 59.0 \%, \mathrm{FEV}_{1} 1.13 \mathrm{~L}$, $\% \mathrm{FEV}_{1}$ 63.2\%, $\mathrm{FEV}_{1} / \mathrm{FVC} 84.9 \%$, DLCO $8.15 \mathrm{~mL} / \mathrm{min} /$ $\mathrm{mmHg}$, and \%DLCO $63.6 \%$.

We suspected drug-induced lung injury and immediately discontinued riluzole, with a plan for follow-up observation in the outpatient clinic. However, after 5 days, both symptoms and radiological findings were unchanged, and the patient was then admitted to our hospital. BAL and transbronchial lung biopsy were then performed. The cell subpopulations containing $11.6 \times 10^{6}$ leukocytes in the BAL fluid comprised macrophages $66.4 \%$, neutrophils $12.0 \%$, lymphocytes $18.1 \%$, eosinophils $3.3 \%$, and mast cells $0.2 \%$, and the ratio of CD4 and CD8 T cells was 0.33. The DLST on the BAL fluid could not be performed due to an insufficient number of lymphocytes. Histological examination of ElasticaMasson (E.M)-stained biopsy specimens from the right S8 region revealed scattered foci of intraalveolar fibrosis in lower view $(\times 20)$ (Fig. 1b). And high power view $(\times 100)$ (Fig. 1c) demonstrated intraalveolar fibrosis adherent to the alveolar septa and thus incorporated into the interstitium. The patient was treated immediately with prednisolone 30 mg daily. After 2 weeks, her general condition and the radiological findings (Fig. 1d) were clearly improved. Nine months later, the prednisolone was tapered to $10 \mathrm{mg} / \mathrm{day}$. At the time of this report, the patient's general condition remains stable.

\section{Case 2}

An 83-year-old woman was diagnosed with ALS 6 months before presentation. Riluzole $50 \mathrm{mg}$ twice daily was started 1 month after the diagnosis. Five weeks after treatment, she presented to us with a 2-week history of a dry cough on exertion.

Physical examination revealed no abnormalities, and oxygen saturation on room air was $98 \%$. Chest CT (Fig. 2a) revealed faint GGO in the right lower lobe. Because we could 

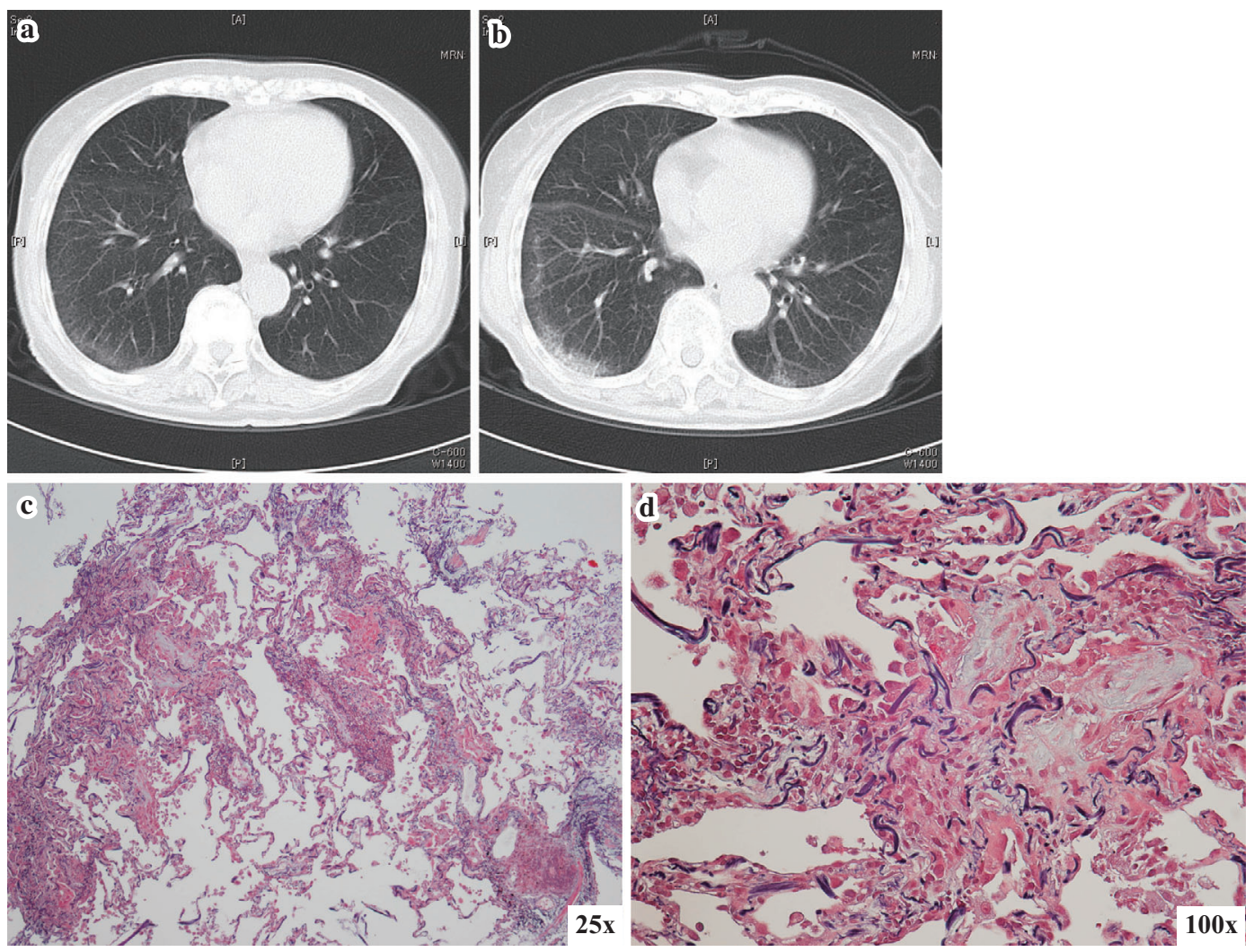

Figure 2. Case 2: radiological and histological images. (a) Chest CT image taken 5 weeks after the start of riluzole therapy. The images reveal slight GGO in the right dorsal lower lobe. Two weeks later, a repeat chest CT scan (b) was performed due to a persistent dry cough and shows consolidation and an increase in GGO which affected the dorsal regions of bilateral lower lobes. (c) Histological examination of E.M-stained biopsy specimens from the right $\mathbf{S 9}$ region revealed scattered foci of intraalveolar fibrosis in low power view $(\times 25)$. (d) The high power view $(\times 100)$ demonstrated intraalveolar fibrosis incorporated into the interstitium, hyperplastic and swollen type II pneumocytes and interstitial lymphocytic infiltration.

diagnose neither a drug-induced lung injury nor communityacquired pneumonia, riluzole was continued and the patient was followed in the outpatient clinic. After 2 weeks, the dry cough persisted, and chest CT (Fig. 2b) revealed increases in both GGO and consolidation in bilateral dorsal lower lobes. Arterial blood gas analysis (nasal $\mathrm{O}_{2} 1 \mathrm{~L} / \mathrm{min}$ ) showed pH 7.413, $\mathrm{PCO}_{2} 43.7$ Torr, $\mathrm{PO}_{2} 106.0$ Torr, $\mathrm{HCO}_{3} 27.4$ $\mathrm{mEq} / \mathrm{L}$, and $\mathrm{BE} 2.9 \mathrm{mEq} / \mathrm{L}$. Additional laboratory results were as follows: white blood cell count $5,700 / \mu 1$ (neutrophils $69.2 \%$, eosinophils $7.7 \%$, lymphocytes $12.4 \%$, monocytes $9.6 \%$, basophils $1.1 \%$ ); creatinine $0.58 \mathrm{mg} / \mathrm{dL}$; lactate dehydrogenase 258 IU/L; KL-6 723 U/mL; SP-D; $66.3 \mathrm{ng} /$ $\mathrm{mL}$; cytoplasmic-anti-neutrophil cytoplasmic antibody $<10$ EU; perinuclear-anti-neutrophil cytoplasmic antibody $<10$ EU; anti-nuclear antibody <20x; SS-A negative; and SI value on DLST 90\% (control $201 \mathrm{cpm}$ vs. riluzole 181 $\mathrm{cpm})$. Pulmonary function data were as follows; FVC 1.54 $\mathrm{L}, \% \mathrm{FVC} 84.6 \%, \mathrm{FEV}_{1} 1.23 \mathrm{~L}, \% \mathrm{FEV}_{1} 90.8 \%$, and $\mathrm{FEV}_{1} /$ FVC $80.0 \%$.

We suspected the patient had a drug-induced lung injury and therefore immediately discontinued riluzole and admitted her to the hospital. One week later, bronchoscopy with BAL and transbronchial lung biopsy were performed. The cell subpopulations containing $7.3 \times 10^{6}$ leukocytes in the BAL fluid comprised macrophages $53.9 \%$, lymphocytes $46.0 \%$, and eosinophils $0.1 \%$. The ratio of CD4 to CD8 T cells was 0.25 . The SI value on DLST of BAL lymphocytes was $485 \%$ (control $370 \mathrm{cpm}$ vs. riluzole 1,796 cpm). Histological examination of E.M-stained biopsy specimens from the right $\mathrm{S} 9$ region revealed scattered foci of intraalveolar fibrosis in lower view $(\times 25)$ (Fig. 2c). And high power view $(\times 100)$ (Fig. 2d) demonstrated intraalveolar fibrosis incorporated into the interstitium, hyperplastic and swollen type II pneumocytes and interstitial lymphocytic infiltration. Prednisolone was started at $20 \mathrm{mg}$ daily. After 2 weeks, her general condition and radiological findings had improved. Two months later, the prednisolone was tapered to $17.5 \mathrm{mg} / \mathrm{day}$. At the time of this report, the patient's general condition remains stable.

\section{Discussion}

Riluzole is the first drug shown to be of benefit in the treatment of ALS (1). To our knowledge, only one report has been published on a possible adverse reaction of hypersensitivity pneumonitis (HP) to riluzole used to treat 
Table 1. Patient Characteristics

\begin{tabular}{|c|c|c|c|c|c|c|c|}
\hline $\begin{array}{l}\text { Patient } \\
\text { No. }\end{array}$ & $\begin{array}{c}\text { Sex } \\
\text { /Age } \\
\text { (years) }\end{array}$ & $\begin{array}{c}\text { Symptoms } \\
\text { /Onset }\end{array}$ & $\begin{array}{l}\text { Radiological } \\
\text { findings }\end{array}$ & $\begin{array}{c}\text { Dose/Duration } \\
\text { of riluzole }\end{array}$ & $* *$ DLST & $\begin{array}{c}\text { Treatment } \\
\text { with } \\
* * * \text { steroid } \\
\text { /Duration } \\
\text { of follow } \\
\text { up }\end{array}$ & $\begin{array}{c}\text { Response to } \\
* * * \text { steroid }\end{array}$ \\
\hline 1 & $\begin{array}{c}\text { Female } \\
\text { /69 }\end{array}$ & $\begin{array}{l}\text { Dyspnea } \\
\text { and } \\
\text { general } \\
\text { fatigue } \\
\text { /Acute }\end{array}$ & $\begin{array}{l}\text { Bilateral lower } \\
\text { lobe, } \\
\text { dorsal-dominant } \\
\text { *GGO and } \\
\text { consolidation. }\end{array}$ & $\begin{array}{c}100 \text { mg daily } \\
\text { /3 weeks }\end{array}$ & $\begin{array}{l}\text { Positive } \\
\text { (Peripheral } \\
\text { blood) } \\
\text { /Not done } \\
\text { (BAL) }\end{array}$ & $\begin{array}{c}30 \mathrm{mg} \\
\text { daily } \\
/ 9 \text { months }\end{array}$ & Effective \\
\hline 2 & $\begin{array}{c}\text { Female } \\
\text { /83 }\end{array}$ & $\begin{array}{l}\text { Dry cough } \\
\text { /Acute }\end{array}$ & $\begin{array}{l}\text { Bilateral lower } \\
\text { lobe, } \\
\text { dorsal-dominant } \\
\text { *GGO and } \\
\text { consolidation }\end{array}$ & $\begin{array}{c}100 \text { mg daily } \\
/ 7 \text { weeks }\end{array}$ & $\begin{array}{l}\text { Negative } \\
\text { (Peripheral } \\
\text { blood) } \\
\text { /Positive } \\
\text { (BAL) }\end{array}$ & $\begin{array}{c}20 \mathrm{mg} \\
\text { daily } \\
/ 2 \text { months }\end{array}$ & Effective \\
\hline
\end{tabular}

*Ground glass opacity, **Drug lymphocyte stimulation test, ***Prednisolone

ALS (2). The pathogenesis of drug-induced lung injury involves one of two pathways: an allergic reaction or cytotoxic effects. Drug-induced lung injury has been reported in association with various immunological abnormalities and as an allergic reaction to Chinese medicines, interferons, antiarrhythmic agents, antibiotics, and disease modifying antirheumatic drugs (3-7). In contrast, anticancer drugs and gold sodium thiomalate directly influence lung tissue through cytotoxic effects $(8,9)$.

Previously, Cassiman et al. reported a case of HP possibly caused by riluzole and diagnosed by histopathological examination of a thoracoscopic lung biopsy specimen (2). The authors discuss that omeprazole, which the patient had been taking, compromises the effects of riluzole by enhancing its metabolism through induction of cytochrome p450 1A2 (2). Although the HP was thought to be due to an increased concentration of riluzole in the blood after the patient's omeprazole was switched to lansoprazole, the present two cases were treated without a cytochrome p450 1A2 inducer or inhibitor, which influenced riluzole's metabolism and blood concentration.

Table 1 shows the similarities between the present two cases. The patients developed symptoms of fatigue and cough or dyspnea on exertion after approximately 2-4 weeks on riluzole, with no history of taking omeprazole. The radiological examinations showed bilateral lower lobe dorsaldominant GGO and consolidation. In comparison to the clinical features reported by Cassiman et al. (2), the onset of respiratory symptoms in the form of dyspnea and/or cough and the efficacy of steroid treatment were similar. On the other hand, the radiological and the histopathological findings in the present cases were not consistent with the specificity findings in HP. Cassiman et al. concluded that the HP reaction does not depend on dosage, but rather on prior sensitization to the agent. In addition to their report, we found that the drug-induced lung diseases caused by riluzole are also dosage dependent.

DLST is a unique in vitro method for identifying the causative drug of adverse reactions $(10,11)$. However, DLST results should be evaluated carefully and with consideration given to the patient's clinical course, as falsenegatives or false-positives may be influenced by many factors such as antigen exposure duration to DLST and some concomitant medications (10). In particular, the results of the present study revealed that the DLST sensitivity for riluzole was positive in PBMCs or BAL lymphocytes. Ideally, we would have a negative control in which patients treated with riluzole lacking respiratory symptoms would have their PBMCs and BAL subject to a DLST. However, we were unable to perform this control, especially on BAL (for comparison to Case 2), for ethical reasons. In Case 2, the DLST sensitivity was negative in PBMCs and positive in BAL lymphocytes. The reason for this discrepancy between the BAL lymphocytes and PBMCs is uncertain; however, we hypothesize that the characteristics of the BAL lymphocytes was different from that of the PBMCs. In other words, the BAL lymphocytes contained a high number of lymphocytes that were specifically sensitized by riluzole. Some reports have shown that a DLST with BAL lymphocytes is useful for diagnosing drug-induced interstitial lung diseases (12-14). We comprehensively considered that the sensitivity of DLST depends on the tested drug or examined disease. Taken together, the pathogenesis of lung injury caused by riluzole might involve a cell-mediated type of allergy. Namely, lymphocytes might be specifically activated by riluzole primarily in lung tissue to produce lymphokines that cause tissue inflammation, and subsequent lung injury. However, the exact mechanism of the riluzole-induced lung injury remains uncertain.

In conclusion, we presented two cases of riluzole-induced 
pneumonitis in ALS. Both cases were acute, had positive DLSTs and histological findings on biopsy consistent with lung injury. To the best of our knowledge, this is the first report of riluzole-induced lung injury with positive DLST results.

The authors state that they have no Conflict of Interest (COI).

\section{References}

1. Cheah BC, Vucic S, Krishnan AV, Kiernan MC. Riluzole, neuroprotection and amyotrophic lateral sclerosis. Curr Med Chem 17: 1942-1959, 2010.

2. Cassiman D, Thomeer M, Verbeken E, Robberecht W. Hypersensitivity pneumonitis possibly caused by riluzole therapy in ALS. Neurology 61: 1150-1151, 2003.

3. Shiota $\mathrm{Y}$, Wilson JG, Matsumoto $\mathrm{H}$, et al. Adult respiratory distress syndrome induced by a Chinese medicine, Kamisyoyo-san. Intern Med 35: 494-496, 1996.

4. Marzouk K, Saleh S, Kannass M, Sharma OP. Interferon-induced granulomatous lung disease. Curr Opin Pulm Med 10: 435-440, 2004.

5. Chang SN, Hwang JJ, Hsu KL, et al. Amiodarone-related pneumonitis. J Formos Med Assoc 106: 411-417, 2007.

6. Suwa A, Hirakata M, Satoh S, et al. Rheumatoid arthritis associ- ated with methotrexate-induced pneumonitis: improvement with i.v. cyclophosphamide therapy. Clin Exp Rheumatol 17: 355-358, 1999.

7. Camus P, Fanton A, Bonniaud P, Camus C, Foucher P. Interstitial lung disease induced by drugs and radiation. Respiration 71: 301326, 2004 .

8. Ghesquieres H. Severe interstitial pneumonitis following rituximab and bleomycin-containing combination chemotherapy. Ann Oncol 16: 1399, 2005.

9. Soler MJ, Barroso E, Aranda FI, Alonso S, Romero S. Fatal, goldinduced pneumonitis. Rheumatol Int 23: 207-210, 2003.

10. Pichler WJ, Tilch J. The lymphocyte transformation test in the diagnosis of drug hypersensitivity. Allergy 59: 809-820, 2004.

11. Beeler A, Pichler WJ. In vitro tests of T-cell-mediated drug hypersensitivity. In: Drug Hypersensitivity. Pichler WJ, Ed. Karger, Basel, 2007: 380-390.

12. Takada N, Arai S, Kusuhara N, et al. A case of sho-saikotoinduced pneumonitis, diagnosed by lymphocyte stimulation test using bronchoalveolar lavage fluid. Nihon Kokyuki Gakkai Zasshi 31: 1163-1169, 1993 (in Japanese, Abstract in English).

13. Kawasaki A, Mizushima Y, Kunitani H, Kitagawa M, Kobayashi M. A useful diagnostic method for drug-induced pneumonitis: a case report. Am J Chin Med 22: 329-336, 1994.

14. Yamamoto Y, Narasaki F, Futsuki Y, et al. Disopyramide-induced pneumonitis, diagnosed by lymphocyte stimulation test using bronchoalveolar lavage fluid. Intern Med 40: 775-778, 2001.

(C) 2012 The Japanese Society of Internal Medicine http://www.naika.or.jp/imindex.html 